\section{Sedentary behavior in adolescents: the 11-year follow-up of the 1993 Pelotas (Brazil) birth cohort study}

\author{
Comportamento sedentário em adolescentes: \\ a visita de 11 anos da coorte de nascimentos de \\ Pelotas, Rio Grande do Sul, Brasil, 1993
}

\author{
1 Programa de Pós-graduação \\ em Epidemiologia \\ Universidade Federal de \\ Pelotas, Pelotas, Brasil. \\ 2 Programa de Pós-graduação \\ em Educação Física, \\ Universidade Federal de \\ Pelotas, Pelotas, Brasil. \\ ${ }^{3}$ Faculdade de Nutrição, \\ Universidade Federal de \\ Pelotas, Pelotas, Brasil. \\ Correspondence \\ S. C. Dumith \\ Programa de Pós-graduação \\ em Epidemiologia, \\ Universidade Federal de \\ Pelotas. \\ Rua Marechal Deodoro 1160, \\ Pelotas, RS 96020-220, Brasil. \\ scdumith@yahoo.com.br
}

\begin{abstract}
The aim of this study was to estimate the prevalence of sedentary behavior and investigate associated factors in adolescents 11 years of age from the 1993 birth cohort in Pelotas, Rio Grande do Sul State, Brazil. Sedentary behavior was investigated with a questionnaire, and was defined as spending more than two hours per day watching television, playing videogames, or using the computer. Of the 4,452 adolescents interviewed, 98\% reported watching television, $44 \%$ playing videogames, and $22 \%$ using the computer. The average time spent on each of these electronic media was 197, 36, and 17 minutes per day, respectively. Prevalence of sedentary behavior was 79.7\% (95\%CI: 78.6; 80.9) and showed a positive association with socioeconomic level and nutritional status and a negative association with well-being. These 11-year-olds spent extensive time at TV viewing, videogames, and the computer. Special attention should be given to the most exposed groups of adolescents, including the more affluent, overweight, and those with limited schooling.
\end{abstract}

Sedentary Lifestyle; Adolescent; Cohort Studies
Samuel C. Dumith 1

Pedro C. Hallal 1,2

Ana M. B. Menezes 1

Cora Luiza Araújo 1,3

\section{Introduction}

Sedentary behavior includes low-intensity activities with reduced calorie expenditure ${ }^{1}$. Television viewing is the most commonly studied indicator, since it represents the single largest share of sedentary behavior 2 , but the latter encompasses not only TV, but also videogames and the computer, reading, listening to music, talking on the telephone, and other activities 3 . The first three activities (TV, videogames, and computer), also known as screen time or electronic media exposure, account for more than half the time spent in sedentary behaviors 4 .

Studies on sedentary behavior are scarce in the literature, especially in developing countries. However, there is strong evidence that greater exposure to sedentary behavior, especially electronic media time (TV, videogames, and computer) can have a harmful effect on health, in both adolescence 5 and adulthood 6 . Additionally, sedentary behavior shows moderate stability during childhood and adolescence, which is known as the tracking effect 7,8,9.

Although most research on sedentary behavior focuses on its association with obesity, electronic media use by children and adolescents also correlates with various other unfavorable health outcomes, including violence and aggressive behavior 10 , early sexual initiation and affected sexuality 11 , increased intake of foods with low nutritional value and high calorie density 12 
distorted body image 13, use of substances like alcohol and cigarettes and other drugs 14, decreased school performance 15 , decreased sleep time 16 , and low physical aptitude 6 .

In response to the growing problem of obesity in childhood and adolescence and other health problems involving electronic media exposure, in 1995 the American Academy of Pediatrics Committee on Communications launched guidelines for limiting screen time to no more than 2 hours/ day for children beginning at two years of age 17 . Even so, it is estimated that the time children and adolescents spend in front of the TV set exceeds the time they spend in school, and that by the time they finish secondary school, they will have spent approximately three years watching television 18. In addition, various studies have shown that sedentary behavior tends to increase during adolescence 7 .

The aim of this study was to determine the prevalence of sedentary behavior and investigate associated factors in adolescents, with a mean age of 11 years, in a birth cohort from southern Brazil.

\section{Methodology}

Subjects in this study are part of a prospective cohort study monitoring all hospital births in 1993 in the city of Pelotas, Rio Grande do Sul State, Brazil. At the time, the mothers answered a questionnaire and the newborns were weighed and measured. Sub-samples of these individuals were visited at 1,3 , and 6 months and 1, 4, 6, and 9 years of age. In 2004-2005, all the cohort members were searched for a new follow-up, the methodological details of which are described elsewhere 19 . The findings presented in this article refer to this last visit, when the mean age of the adolescents was 11 years.

The principal variable - sedentary behavior - was collected through face-to-face interviews using a previously tested and standardized questionnaire. This instrument included questions about whether the adolescent watched TV, played videogames, and used the computer. The mean time spent in front of each of these electronic media (in a typical week) was asked separately for weekdays and weekends. The outcomes were constructed by adding the weighted mean screen time (TV + videogame + computer), assigning weight 5 to weekdays and weight 2 to weekends and dividing the result by 7 to obtain the mean time in minutes per day. The cutoff used to define sedentary behavior was screen time greater than 2 hours/day, in accordance with international guidelines for this age bracket 17 . An additional analysis was performed using a cutoff of 4 hours / day, for purposes of comparison.

To investigate factors associated with sedentary behavior, the following data were collected: demographic (gender and skin color), socioeconomic (assets index, constructed from a principal components analysis involving 18 indicators of socioeconomic status), family (how the adolescent was raised as compared to friends the same age), environmental (whether the adolescent likes the neighborhood where he or she lives), behavioral (level of physical activity greater versus less than 300 minutes/week), nutritional (nutritional status), and health (level of well-being, measured with the faces scale, from 1 to 7 in decreasing order).

The data were analyzed in three different ways. First, we described the percentage of adolescents that watched TV, played videogames, and used the computer. The chi-square test was used to compare the proportions among the categories of independent variables. Next, we present the mean time (in minutes/day) spent at each of these electronic media, and compare the means using the ANOVA test. Finally, we analyze the prevalence of sedentary behavior (with cutoffs of 2 hours/day and 4 hours/day) according to the target factors. In this case, both the crude and adjusted analyses were performed using Poisson regression with robust variance 20.

We should highlight that in order to adjust for possible confounders a conceptual model was elaborated that determines the order of the variables' entry into the multivariate analysis. This model consists of various levels, organized hierarchically according to the causal sequence in each factor's influence on the outcome 21 . The first (more distal) level includes the demographic and socioeconomic factors (gender, skin color, and assets index); the intermediate level includes the family and environmental factors (upbringing and liking the neighborhood); and the more proximal contains the behavioral (physical activity), nutritional (nutritional status), and health characteristics (well-being). Each variable was controlled for those at the same level or above, and all were submitted to analysis, keeping in the model only those with a p-value less than 0.2022 . Significance was set at $5 \%$, and all the analyses were performed with Stata, version 9.2 (Stata Corp., College Station, USA).

The research was approved by the Institutional Review Board of the School of Medicine at the Federal University in Pelotas. Parents or guardians signed a free and informed consent form authorizing the children to participate in the study. 


\section{Results}

Of the 4,452 adolescents interviewed, complete information on outcome was obtained for 4,431 (99.5\%). The proportions that watched TV, played videogames, and used the computer were $98.2 \%$, $43.9 \%$, and $22.4 \%$, respectively (Table 1 ). Factors associated with watching more TV were: higher income, being raised more indoors, liking one's neighborhood, and obesity. Playing videogames was associated with male gender, white skin color, higher household assets index, physical activity, and obesity. Computer use was more frequent among white, upper-class, overweight or obese boys with intermediate well-being scores.
As for the various electronic media, the adolescents spent an average of more than 3 hours/ day watching TV, 30 minutes playing videogames, and 15 minutes on the computer (Table 2). While girls watched more TV, boys spent more time on videogames and the computer. The same was true for those raised more indoors as compared to those with a freer upbringing. TV time did not differ according to skin color or household assets index, but white and more affluent adolescents spent more time playing videogames and using the computer. Liking the neighborhood was not associated with any of the target behaviors. Physically active adolescents watched less TV but spent more time playing videogames. As for

Table 1

Proportion of adolescents that watch television, play videogames, or use the computer, according to target characteristics. 1993 Pelotas (Brazil) birth cohort study, 2004-2005 follow-up.

\begin{tabular}{|c|c|c|c|}
\hline Variable & Television (\%) & Videogames (\%) & Computer (\%) \\
\hline Gender & $p=0.134$ & $p<0.001$ & $p=0.023$ \\
\hline Male & 97.9 & 58.5 & 23.9 \\
\hline Female & 98.5 & 29.8 & 21.0 \\
\hline Skin color & $p=0.087$ & $p<0.001$ & $p<0.001$ \\
\hline White & 98.5 & 46.3 & 27.4 \\
\hline Black/Brown & 97.6 & 38.7 & 12.1 \\
\hline Assets index (quintiles) & $p<0.001$ & $p<0.001$ & $p<0.001$ \\
\hline 1st (lowest) & 95.6 & 34.1 & 5.2 \\
\hline $2^{\text {nd }}$ & 97.9 & 39.0 & 9.1 \\
\hline 3 rd & 99.5 & 43.6 & 9.1 \\
\hline $4^{\text {th }}$ & 99.4 & 53.1 & 19.7 \\
\hline $5^{\text {th }}$ & 100.0 & 52.2 & 71.0 \\
\hline Upbringing & $p=0.035$ & $p<0.001$ & $p=0.077$ \\
\hline Freer & 97.5 & 50.6 & 24.3 \\
\hline More indoors & 98.4 & 41.6 & 21.8 \\
\hline Likes the neighborhood & $p=0.005$ & $p=0.623$ & $p=0.570$ \\
\hline No & 97.1 & 44.7 & 21.7 \\
\hline Yes & 98.5 & 43.8 & 22.6 \\
\hline Level of physical activity & $p=0.933$ & $p<0.001$ & $p=0.098$ \\
\hline Inactive & 98.2 & 39.6 & 23.7 \\
\hline Active & 98.3 & 49.4 & 21.5 \\
\hline Nutritional status & $p=0.012$ & $p<0.001$ & $p<0.001$ \\
\hline Underweight & 96.2 & 43.0 & 21.2 \\
\hline Normal & 98.2 & 42.3 & 20.5 \\
\hline Overweight & 98.6 & 44.6 & 27.8 \\
\hline Obese & 99.2 & 53.4 & 28.9 \\
\hline Well-being & $p=0.112$ & $p=0.122$ & $p<0.001$ \\
\hline 1 (happiest) & 97.8 & 42.5 & 20.4 \\
\hline 2 & 98.7 & 45.8 & 26.3 \\
\hline$\geq 3$ & 98.4 & 44.6 & 20.0 \\
\hline Total & 98.2 & 43.9 & 22.4 \\
\hline
\end{tabular}


Time (minutes/day) for each sedentary behavior and the combination of the three (watching television, playing videogames and using the computer), according to categories of independent variables. 1993 Pelotas (Brazil) birth cohort study, 20042005 follow-up.

\begin{tabular}{|c|c|c|c|c|}
\hline Variable & $\begin{array}{l}\text { Television } \\
\text { Mean (SD) }\end{array}$ & $\begin{array}{c}\text { Videogames } \\
\text { Mean (SD) }\end{array}$ & $\begin{array}{l}\text { Computer } \\
\text { Mean (SD) }\end{array}$ & $\begin{array}{l}\text { Screen time } \\
\text { Mean (SD) }\end{array}$ \\
\hline Gender & $p<0.001$ & $p<0.001$ & $p<0.001$ & $p<0.001$ \\
\hline Male & 190 (119) & $55(82)$ & $20(53)$ & $265(164)$ \\
\hline Female & 203 (119) & $18(40)$ & $13(38)$ & $234(135)$ \\
\hline Skin color & $p=0.095$ & $p=0.001$ & $p<0.001$ & $p<0.001$ \\
\hline White & $199(117)$ & $39(67)$ & $21(52)$ & $258(151)$ \\
\hline Black/Brown & $192(122)$ & $31(63)$ & $8(30)$ & $231(148)$ \\
\hline Assets index (quintiles) & $p=0.263$ * & $p<0.001 *$ & $p<0.001$ * & $p<0.001$ * \\
\hline 1st (lowest) & $185(122)$ & $26(56)$ & $3(16)$ & $215(138)$ \\
\hline $2^{\text {nd }}$ & $202(122)$ & $33(64)$ & $4(18)$ & $239(145)$ \\
\hline 3 rd & $200(121)$ & $37(71)$ & $5(24)$ & $243(148)$ \\
\hline $4^{\text {th }}$ & $206(119)$ & 45 (69) & $10(30)$ & $261(147)$ \\
\hline 5 th & $190(105)$ & $43(70)$ & $62(80)$ & $295(162)$ \\
\hline Upbringing & $p<0.001$ & $p=0.001$ & $p=0.008$ & $p=0.127$ \\
\hline Freer & $182(118)$ & $42(67)$ & $20(53)$ & $244(156)$ \\
\hline More indoors & $202(119)$ & $34(65)$ & $16(43)$ & $252(149)$ \\
\hline Likes the neighborhood & $p=0.232$ & $p=0.143$ & $p=0.457$ & $p=0.072$ \\
\hline No & $201(125)$ & $39(74)$ & $18(49)$ & 258 (159) \\
\hline Yes & $196(117)$ & $36(64)$ & $16(46)$ & 247 (149) \\
\hline Level of physical activity & $p=0.002$ & $p<0.001$ & $p=0.103$ & $p=0.736$ \\
\hline Inactive & $201(120)$ & $30(57)$ & $18(48)$ & $249(146)$ \\
\hline Active & 190 (117) & $45(76)$ & $15(44)$ & 250 (157) \\
\hline Nutritional status & $p=0.015$ & $p<0.001$ & $p=0.002$ & $p<0.001$ \\
\hline Underweight & $188(120)$ & $33(72)$ & $17(48)$ & $238(164)$ \\
\hline Normal & 194 (119) & $35(65)$ & $15(44)$ & 244 (149) \\
\hline Overweight & 209 (117) & $33(57)$ & $19(45)$ & 261 (139) \\
\hline Obese & 204 (120) & 49 (73) & $23(54)$ & $276(162)$ \\
\hline Well-being scale & $p<0.001$ * & $p=0.019$ * & $p=0.012$ * & $p<0.001$ * \\
\hline 1 (happiest) & $187(117)$ & $34(63)$ & $14(42)$ & $235(146)$ \\
\hline 2 & $202(119)$ & $37(66)$ & $20(51)$ & $260(151)$ \\
\hline$\geq 3$ & $217(123)$ & $41(74)$ & $16(46)$ & $274(161)$ \\
\hline Total & 197 (119) & $36(66)$ & $17(46)$ & $249(151)$ \\
\hline
\end{tabular}

SD: standard deviation.

* $p$-value for linear trend.

nutritional status, obese adolescents spent more time front of the TV, videogames, and computer. Screen time was inversely related to level of well-being.

Considering total screen time, kids spent an average of more than 4 hours/day in front of the $\mathrm{TV}$, videogames, or computer (last column, Table 2). Time was greater for boys, whites, and the obese. It also increased according to household assets index and decreased according to level of well-being.
Overall prevalence of sedentary behavior (screen time $\geq 2$ hours/day) was $79.7 \%$ (95\% confidence level, 95\%CI: 78.6; 80.9). Table 3 shows the results of the sedentary behavior analysis according to target factor categories. According to the crude analysis, prevalence was higher among white, more affluent, and overweight adolescents and those that did not classify themselves as very happy. In the adjusted analysis, skin color lost the association after controlling for assets index. The other variables (gender, upbringing, liking 
Table 3

Prevalence of sedentary behavior (screen time greater than 2 hours/day) according to target factors. 1993 Pelotas (Brazil) cohort study, 2004-2005 follow-up.

\begin{tabular}{|c|c|c|c|c|c|}
\hline \multirow[t]{2}{*}{ Variable } & \multirow[t]{2}{*}{ Prevalence (\%) } & \multicolumn{2}{|c|}{ Crude analysis } & \multicolumn{2}{|c|}{ Adjusted analysis } \\
\hline & & PR $(95 \% \mathrm{Cl})$ & p-value & PR (95\%Cl) & $p$-value \\
\hline Gender & & & 0.127 & & 0.095 \\
\hline Male & 80.7 & $1.02(0.99 ; 1.05)$ & & $1.03(1.00 ; 1.06)$ & \\
\hline Female & 78.8 & 1.00 & & 1.00 & \\
\hline Skin color & & & $<0.001$ & & 0.171 \\
\hline White & 81.5 & $1.07(1.03 ; 1.11)$ & & $1.03(0.99 ; 1.06)$ & \\
\hline Black/Brown & 76.2 & 1.00 & & 1.00 & \\
\hline Assets index (quintiles) & & & $<0.001 *$ & & $<0.001$ * \\
\hline 1st (lowest) & 70.6 & 1.00 & & 1.00 & \\
\hline $2^{\text {nd }}$ & 78.9 & $1.12(1.06 ; 1.18)$ & & $1.12(1.06 ; 1.18)$ & \\
\hline 3 rd & 79.0 & $1.12(1.06 ; 1.18)$ & & $1.11(1.05 ; 1.18)$ & \\
\hline $4^{\text {th }}$ & 83.9 & $1.19(1.13 ; 1.25)$ & & $1.18(1.12 ; 1.24)$ & \\
\hline $5^{\text {th }}$ & 88.5 & $1.25(1.19 ; 1.32)$ & & $1.24(1.18 ; 1.30)$ & \\
\hline Upbringing & & & 0.065 & & 0.174 \\
\hline Freer & 77.9 & 1.00 & & 1.00 & \\
\hline More indoors & 80.5 & $1.03(1.00 ; 1.07)$ & & $1.03(0.99 ; 1.06)$ & \\
\hline Likes the neighborhood & & & 0.238 & & 0.411 \\
\hline No & 78.3 & $0.98(0.94 ; 1.02)$ & & $0.98(0.95 ; 1.02)$ & \\
\hline Yes & 80.2 & 1.00 & & 1.00 & \\
\hline Level of physical activity & & & 0.473 & & 0.915 \\
\hline Inactive & 80.1 & $1.01(0.98 ; 1.04)$ & & $1.00(0.97 ; 1.03)$ & \\
\hline Active & 79.2 & 1.00 & & 1.00 & \\
\hline Nutritional status & & & $<0.001$ * & & 0.002 * \\
\hline Underweight & 76.6 & 1.00 & & 1.00 & \\
\hline Normal & 78.4 & $1.02(0.96 ; 1.09)$ & & $1.02(0.96 ; 1.09)$ & \\
\hline Overweight & 83.3 & $1.09(1.01 ; 1.17)$ & & $1.06(0.98 ; 1.14)$ & \\
\hline Obese & 85.8 & $1.12(1.04 ; 1.20)$ & & $1.08(1.00 ; 1.16)$ & \\
\hline Well-being scale & & & $<0.001$ * & & $<0.001$ * \\
\hline 1 (happiest) & 76.6 & 1.00 & & 1.00 & \\
\hline 2 & 82.4 & $1.08(1.04 ; 1.11)$ & & $1.06(1.03 ; 1.10)$ & \\
\hline$\geq 3$ & 84.4 & $1.10(1.06 ; 1.15)$ & & $1.10(1.05 ; 1.14)$ & \\
\hline Total & 79.7 & - & - & - & - \\
\hline
\end{tabular}

PR: prevalence ratio; $95 \% \mathrm{Cl}$ : 95\% confidence interval.

* $\mathrm{p}$-value for linear trend.

one's neighborhood, and level of physical activity) were not statistically associated with sedentary behavior.

When considering the 4 hours/day cutoff, prevalence of sedentary behavior was $47.2 \%$ (95\%CI: 45.7 ; 48.7). Most of the associations showed similar results to those in the previous paragraph for Table 3. However, some differences appeared in relation to gender, liking one's neighborhood, and nutritional status (Table 4). Prevalence was $15 \%$ greater in boys than girls; those that reported not liking the neighborhood were more prone to exceeding the cutoff; and nutritional status lost its association in the adjusted analysis (Table 4).

\section{Discussion}

This is one of the first studies on the association between sedentary behavior and demographic, socioeconomic, family, environmental, nutritional, behavioral, and health characteristics in a sample of Brazilian adolescents. Most studies on 
Prevalence of sedentary behavior (screen time greater than 4 hours/day) according to target factors. 1993 Pelotas (Brazil) birth cohort study, $2004-2005$ follow-up.

\begin{tabular}{|c|c|c|c|c|c|}
\hline \multirow[t]{2}{*}{ Variable } & \multirow[t]{2}{*}{ Prevalence (\%) } & \multicolumn{2}{|c|}{ Crude analysis } & \multicolumn{2}{|c|}{ Adjusted analysis } \\
\hline & & PR $(95 \% \mathrm{Cl})$ & p-value & PR (95\%Cl) & $p$-value \\
\hline Gender & & & $<0.001$ & & $<0.001$ \\
\hline Male & 50.5 & $1.15(1.08 ; 1.22)$ & & $1.14(1.07 ; 1.22)$ & \\
\hline Female & 44.0 & 1.00 & & 1.00 & \\
\hline Skin color & & & $<0.001$ & & 0.087 \\
\hline White & 49.6 & $1.16(1.08 ; 1.25)$ & & $1.07(0.99 ; 1.16)$ & \\
\hline Black/Brown & 42.6 & 1.00 & & 1.00 & \\
\hline Assets index (quintiles) & & & $<0.001$ * & & $<0.001$ * \\
\hline 1st (lowest) & 39.1 & 1.00 & & 1.00 & \\
\hline $2^{\text {nd }}$ & 44.1 & $1.13(1.01 ; 1.26)$ & & $1.13(1.01 ; 1.26)$ & \\
\hline 3 rd & 42.6 & $1.09(0.97 ; 1.22)$ & & $1.08(0.96 ; 1.21)$ & \\
\hline $4^{\text {th }}$ & 50.8 & $1.30(1.17 ; 1.44)$ & & $1.29(1.15 ; 1.43)$ & \\
\hline $5^{\text {th }}$ & 59.8 & $1.53(1.38 ; 1.69)$ & & $1.49(1.34 ; 1.65)$ & \\
\hline Upbringing & & & 0.062 & & 0.094 \\
\hline Freer & 44.8 & 1.00 & & 1.00 & \\
\hline More indoors & 48.1 & $1.07(1.00 ; 1.15)$ & & $1.07(0.99 ; 1.15)$ & \\
\hline Likes the neighborhood & & & 0.068 & & 0.018 \\
\hline No & 49.9 & $1.07(1.00 ; 1.16)$ & & $1.10(1.02 ; 1.18)$ & \\
\hline Yes & 46.5 & 1.00 & & 1.00 & \\
\hline Active ( $\geq 300$ minutes/week) & & & 0.309 & & 0.534 \\
\hline No & 46.4 & 1.00 & & 1.00 & \\
\hline Yes & 48.0 & $1.03(0.97 ; 1.10)$ & & $1.02(0.96 ; 1.09)$ & \\
\hline Nutritional status & & & $<0.001 *$ & & $0.123 *$ \\
\hline Underweight & 43.6 & 1.00 & & 1.00 & \\
\hline Normal & 45.7 & $1.05(0.92 ; 1.20)$ & & $1.01(0.88 ; 1.15)$ & \\
\hline Overweight & 52.9 & $1.22(1.05 ; 1.41)$ & & $1.11(0.96 ; 1.25)$ & \\
\hline Obese & 52.4 & $1.20(1.04 ; 1.40)$ & & $1.05(0.90 ; 1.23)$ & \\
\hline Well-being scale & & & $<0.001 *$ & & $<0.001$ * \\
\hline 1 (happiest) & 42.7 & 1.00 & & 1.00 & \\
\hline 2 & 50.6 & $1.19(1.11 ; 1.27)$ & & $1.15(1.07 ; 1.23)$ & \\
\hline$\geq 3$ & 54.8 & $1.29(1.18 ; 1.41)$ & & $1.27(1.16 ; 1.39)$ & \\
\hline Total & 47.2 & - & - & - & - \\
\hline
\end{tabular}

PR: prevalence ratio; $95 \% \mathrm{Cl}$ : $95 \%$ confidence interval.

* $p$-value for linear trend.

this theme have been done in developed countries like the United States and Australia 7,8,9,12,16 with rare studies in developing countries.

A positive aspect of this study is the threeway analysis of sedentary behavior. First, we analyzed factors associated with TV, videogames, and the computer. Next, we analyzed the mean time spent daily at each of these electronic media separately and all three combined (screen time) according to the independent variables. Finally, screen time was dichotomized (according to two cutoff) and the associations with the study variables were established. However, the lack of psychometric indicators (reproducibility and validity) in the instrument used to measure sedentary behavior posed a limitation to the current study.

It is difficult to compare the findings from the first and second way of operationalizing the outcome (continuous variable) with those in the literature, since most studies have analyzed sedentary behavior by categorizing it according to a given cutoff $7,23,24$. Among the studies that have measured prevalence of sedentary behav- 
ior using the 2 hours/day cutoff, a major survey focused on adolescents 11 to 15 years of age in 32 countries including the Europe continent, United States, Canada, and Israel 24. Sedentary behavior varied from $40 \%$ (Switzerland) to $80 \%$ (Ukraine). However, the study only considered TV viewing time. In an Australian study focusing on 8-to-13-year-olds, prevalence of sedentary behavior (considering TV, videogames, and the computer) was $82 \% 7$. This finding is consistent with that of our study (80\%). However, considering the mean total sedentary behavior time, the results are slightly different (23.8 hours/week in the Australian study versus 29.1 hours/week in the current study).

In Brazil, a study of adolescents 15 to 19 years of age in the State of Santa Catarina found $73 \%$ prevalence of sedentary behavior (screen time greater than 2 hours/day), with no difference by gender 25. Another population-based study in Pelotas with adolescents 10 to 19 years of age detected $75 \%$ prevalence of sedentary behavior (TV time greater than 2 hours/day) $75 \% 243$. If the current study had considered only TV time to define sedentary behavior, the prevalence would have been some $70 \%$, very close to that of the previously cited study.

As for factors associated with sedentary behavior, a systematic review published in 2004 reached the following conclusions: prevalence of sedentary behavior (estimated as TV viewing time) was greater for individuals 9 to 13 years of age, with lower socioeconomic status, from families with separated parents, from ethnic minorities, with a TV in the child's room, and with higher body weight 2 . Another recent systematic review found that sedentary behavior in adolescents (including TV, videogames and computer) was more frequent among boys, non-Caucasians and was directly associated with body mass index (BMI) and inversely associated with socioeconomic status and parents' schooling 26 .

The positive association between sedentary behavior and socioeconomic status in this study differs from that reported by the two above-mentioned systematic reviews. A possible explanation for this discrepancy is the fact that most of the studies came from countries in which the population's purchasing power is much higher than in Brazil. Thus, in the developed countries, lower-income people have greater access to electronic media devices, unlike Brazil, where many poor people lack home videogames and computers. The same arguments apply to skin color, since individuals from ethnic minorities in developed countries are more exposed to sedentary behavior, contrary to the Brazilian context, where whites are at greater risk.
When the factors included in the creation of the sedentary behavior variable are analyzed separately, some peculiarities emerge. For example, while girls watch more TV, boys spend more time at videogames and the computer. This can probably be explained by cultural aspects and deserves a qualitative approach in order to understand it better. Importantly, there was no association between gender and screen time using the 2 hours/day criterion, but when the 4 hours/ day cutoff was used, boys showed a higher prevalence of sedentary behavior.

Another important observation is that active adolescents watch less TV, but spend more time playing videogames. A similar finding was reported in a study of Canadian adolescents 27. The explanation for this phenomenon is not totally clear, but videogames clearly involve more action and energy expenditure than watching TV. Another hypothesis is that videogames featuring sports may encourage playing sports in real life. However, when screen time was analyzed as a single variable, there was no association with physical activity, which is also consistent with the literature, since they are two different and independent behaviors 28 .

As for liking one's neighborhood, this variable did not show an association with the time spent on each of the electronic media or with sedentary behavior. However, considering the 4 hours/day cutoff for screen time, adolescents that reported not liking their neighborhood showed $10 \%$ higher odds of exceeding this cutoff. This finding may explain the effect that environmental factors (e.g. place of residence) have on individual behavior, even among school-age children.

The positive association in the current study between nutritional status and sedentary behavior is consistent with the literature 2,26. However, sedentary behavior may not only be a risk factor for obesity 1 , but also be caused by it 7 . However, the current study design did not allow making causal inferences, since the association was analyzed at a single moment. Thus, the absence of association based on the 4 hours/day cutoff may be explained by a possible reverse causality effect, namely, obese adolescents may have reduced the time spent at the electronic media due to their excess weight, either at their own initiative or due to recommendations by others.

The inverse association between well-being and sedentary behavior was also an interesting finding. Less happy adolescents were the ones with the most screen time, regardless of which media (TV, videogame, or computer). This association could also be interpreted in the other direction, since all the factors were measured at the same moment, and it was not possible to es- 
tablish a temporal relationship between the two phenomena. Thus, it could be that adolescents that spend more time at TV, videogames, and the computer, which are sedentary and individual activities, acquire a lower level of well-being.

The identification of factors associated with sedentary behavior, especially those considered modifiable (environmental factors, for example) may contribute effectively to the implementation of strategies and programs that aim to combat excess sedentary behavior in childhood and adolescence and consequently help reduce the high levels of adiposity observed in this age group 29 . However, regardless of the adolescent's characteristics, both screen time and prevalence of sed- entary behavior were substantially high, varying respectively from 3.5 to 5 hours/day and from $71 \%$ to $89 \%$. Even considering the 4 hours/day cutoff, nearly half the adolescents in our sample exceeded this level.

Finally, we recommend further research on this issue, since the associated factors have still not been fully elucidated and may vary according to the specific study context. In addition, as found in the current study, sedentary behavior affects a large proportion of children in early adolescence. Longitudinal studies are also useful for better identifying the determinants and mediators of change in this behavior during adolescence, as well as its effect in adulthood.

\section{Resumo}

O objetivo deste estudo foi determinar a prevalência e investigar os fatores associados ao comportamento sedentário em adolescentes de 11 anos, pertencentes à coorte de nascimentos de 1993 de Pelotas, Rio Grande do Sul, Brasil. O comportamento sedentário foi coletado por meio de questionário, e definido como ficar mais de duas horas por dia assistindo à televisão, jogando videogame ou usando computador. Dos 4.452 adolescentes entrevistados, 98\% assistiam à televisão, $44 \%$ jogavam videogame $e 22 \%$ usavam computador. O tempo médio na frente de cada um desses meios eletrônicos foi, respectivamente, 197, 36 e 17 minutos por dia. A prevalência de comportamento sedentário foi de 79,7\% (IC95\%: 78,6; 80,9), e teve uma associação positiva com nível socioeconômico e com estado nutricional, e negativa com a escala de bem-estar. $O$ tempo despendido em atividades como ver televisão, jogar videogame e usar computador foi elevado (média superior a 4 horas/dia). Maior atenção deve ser dada aos grupos mais expostos, tais como adolescentes de classe alta, acima do peso e com menor nível de bem-estar.

Estilo de Vida Sedentário; Adolescente; Estudos de Coortes

\section{Contributors}

S. C. Dumith performed the analysis and wrote the article. P. C. Hallal, A. M. B. Menezes, and C. L. Araújo coordinated the fieldwork and critically revised the article.

\section{Acknowledgments}

The cohort study is supported by the Wellcome Trust. The initial phases of the cohort were funded by the European Union and the Brazilian National Program for Centers of Excellence (PRONEX), National Research Council (CNPq), and Ministry of Health. The lead author wishes to thank the CNPq and the Coordinating Division for Graduate Studies (CAPES) for the assistance provided through a scholarship. 


\section{References}

1. Must A, Tybor DJ. Physical activity and sedentary behavior: a review of longitudinal studies of weight and adiposity in youth. Int J Obes (Lond) 2005; 29 Suppl 2:S84-96.

2. Gorely T, Marshall SJ, Biddle SJ. Couch kids: correlates of television viewing among youth. Int J Behav Med 2004; 11:152-63.

3. Ainsworth BE, Haskell WL, Leon AS, Jacobs Jr. DR, Montoye HJ, Sallis JF, et al. Compendium of physical activities: classification of energy costs of human physical activities. Med Sci Sports Exerc 1993; 25:71-80.

4. Norman GJ, Schmid BA, Sallis JF, Calfas KJ, Patrick K. Psychosocial and environmental correlates of adolescent sedentary behaviors. Pediatrics 2005; 116:908-16.

5. Brodersen NH, Steptoe A, Williamson S, Wardle J. Sociodemographic, developmental, environmental, and psychological correlates of physical activity and sedentary behavior at age 11 to 12 . Ann Behav Med 2005; 29:2-11.

6. Hancox RJ, Milne BJ, Poulton R. Association between child and adolescent television viewing and adult health: a longitudinal birth cohort study. Lancet 2004; 364:257-62.

7. Hesketh K, Wake M, Graham M, Waters E. Stability of television viewing and electronic game/computer use in a prospective cohort study of Australian children: relationship with body mass index. Int J Behav Nutr Phys Act 2007; 4:60.

8. Janz KF, Burns TL, Levy SM. Tracking of activity and sedentary behaviors in childhood: the Iowa Bone Development Study. Am J Prev Med 2005; 29:171-8.

9. Raudsepp L, Neissaar I, Kull M. Longitudinal stability of sedentary behaviors and physical activity during early adolescence. Pediatr Exerc Sci 2008; 20:251-62.

10. Donnerstein E. The mass media: a role in injury causation and prevention. Adolesc Med 1995; 6:271-84

11. Brown JD, Greenberg BS, Buerkel-Rothfuss NL. Mass media, sex, and sexuality. Adolesc Med 1993; 4:511-26.

12. Andersen RE, Crespo CJ, Bartlett SJ, Cheskin LJ, Pratt M. Relationship of physical activity and television watching with body weight and level of fatness among children: results from the Third National Health and Nutrition Examination Survey. JAMA 1998; 279:938-42.

13. Harrison K, Cantor J. The relationship between media consumption and eating disorders. J Commun 1997; 47:40-68.

14. Strasburger VC. "Sex, drugs, rock ' $n$ ' roll" and the media: are the media responsible for adolescent behavior? Adolesc Med 1997; 8:403-14.

15. Morgan M. Television and school performance. Adolesc Med 1993; 4:607-22.

16. Nelson MC, Gordon-Larsen P. Physical activity and sedentary behavior patterns are associated with selected adolescent health risk behaviors. Pediatrics 2006; 117:1281-90.
17. Children, adolescents, and television. American Academy of Pediatrics Committee on Communications. Pediatrics 1995; 96(4 Pt 1):786-7.

18. Strasburger VC. Children, adolescents, and the media: five crucial issues. Adolesc Med 1993; 4: 479-93.

19. Araújo CL, Menezes AMB, Vieira MFA, Neutzling MB, Gonçalves H, Anselmi L, et al. The 11-year follow-up of the 1993 Pelotas (Brazil) birth cohort study: methods. Cad Saúde Pública 2010; 26: 1875-86.

20. Barros AJ, Hirakata VN. Alternatives for logistic regression in cross-sectional studies: an empirica comparison of models that directly estimate the prevalence ratio. BMC Med Res Methodol 2003; 3:21.

21. Victora CG, Huttly SR, Fuchs SC, Olinto MT. The role of conceptual frameworks in epidemiological analysis: a hierarchical approach. Int J Epidemiol 1997; 26:224-7.

22. Maldonado G, Greenland S. Simulation study of confounder-selection strategies. Am J Epidemiol 1993; 138:923-36.

23. Dutra CL, Araújo CL, Bertoldi AD. Prevalência de sobrepeso em adolescentes: um estudo de base populacional em uma cidade no Sul do Brasil. Cad Saúde Pública 2006; 22:151-62.

24. Vereecken CA, Todd J, Roberts C, Mulvihill C, Maes L. Television viewing behaviour and associations with food habits in different countries. Public Health Nutr 2006; 9:244-50.

25. Silva KS, Nahas MV, Hoefelmann LP, Lopes AS, Oliveira ES. Associações entre atividade física, índice de massa corporal e comportamentos sedentários em adolescentes. Rev Bras Epidemiol 2008; 11 : 159-68.

26. Van Der Horst K, Paw MJ, Twisk JW, Van Mechelen W. A brief review on correlates of physical activity and sedentariness in youth. Med Sci Sports Exerc 2007; 39:1241-50.

27. O'Loughlin J, Paradis G, Kishchuk N, Barnett T, Renaud L. Prevalence and correlates of physical activity behaviors among elementary schoolchildren in multiethnic, low income, inner-city neighborhoods in Montreal, Canada. Ann Epidemiol 1999; 9:397-407.

28. Taveras EM, Field AE, Berkey CS, Rifas-Shiman SL, Frazier AL, Colditz GA, et al. Longitudinal relationship between television viewing and leisure-time physical activity during adolescence. Pediatrics 2007; 119:e314-9.

29. Duquia RP, Dumith SC, Reichert FF, Madruga SW Duro LN, Menezes AMB, et al. Epidemiologia das pregas cutâneas tricipital e subescapular elevadas em adolescentes. Cad Saúde Pública 2008; 24: 113-21.

Submitted on 31/Jan/2009

Final version resubmitted on 21/Aug/2009

Approved on 01/Sep/2009 